\title{
El inconsciente relacional en las relaciones de pareja en la generación de las "mujeres Disney"1
}

\author{
Aleksandra Misiolek \\ IARPP-E, Barcelona
}

\begin{abstract}
El objetivo de este artículo es mostrar cómo trabajo con las llamadas "mujeres Disney" - pacientes que vienen aquejadas de las relaciones de pareja insatisfactorias, en las cuales no se sienten suficientemente queridas por su pareja y desconfían de él y sienten celos. Por sus inseguridades crean un círculo vicioso o un bucle de feedback donde por el miedo a ser abandonadas acaban creando la profecía autocumplida y llevan la relación al fracaso.

En su infancia, estas chicas recurrieron al mundo de la fantasía, fomentado por las películas de Disney, como una vía de escape de la falta de un apego seguro y por falta de sintonía en la relación. Su inconsciente relacional necesita "aprender" una nueva forma de estar en el mundo que pretendemos facilitarles con la terapia. Defiendo que en cada sesión terapéutica pretendemos ofrecer una experiencia relacional correctora en un lugar seguro y con un apego seguro con el terapeuta.
\end{abstract}

Palabras clave: Inconsciente relaciones, Relaciones de pareja, Generación Disney, Mujeres

The aim of this article is to show how I work with the so called "Disney women" - patients that come to therapy because of unsatisfactory couple relationahips, in which they do not feel loved enough by their partners and they distrust them and feel jealous. Because of their insecurities, they create a vicious circle or a loop of feedback in which, because of the self-fulfilled prophesy they end up creating, they make the relationship fail. In their childhood, these women used the world of fantasy, fomented by the Disney movies, as a way of escaping from the lack of secure attachment and malattunement in the relationship. Their relational inconscience needs to "learn" a new way of being in the world that we intent to provide in therapy. I defend that each psychotherapy session should offer a corrective relational experience in a secure place and within a secure attachment with the therapist.

Key Words: Relational Unconscious, Couple Relationships, Disney Generation, Women English Title: The relational unconscious in couple relationships in "Disney women" generation.

\section{Cita bibliográfica / Reference citation:}

Misiolek, A. (2017). El inconsciente relacional en las relaciones de pareja en la generación de las "Mujeres Disney". Clínica e Investigación Relacional, 11 (3): 537-545. [ISSN 1988-2939] [Recuperado de www.ceir.info ] DOI: 10.21110/19882939.2017.110305

\footnotetext{
${ }^{1}$ Trabajo presentado en la VII reunión bienal de IARPP-España, celebrada en Barcelona, Abril 2017. Los nombres y varios datos de mis pacientes han sido cambiados para proteger su identidad.
} 
El objetivo de este artículo es, por un lado, describir y analizar las ideas falsas sobre el amor que tienen las chicas que crecieron con las películas Disney y en las familias emocionalmente complicadas, y qué problemáticas esto crea en sus relaciones de pareja, y, por otro, mostrar cómo trabajo con ellas en terapia.

Las "Mujeres Disney" es el término que he acuñado para llamar a las mujeres jóvenes de entre 20 y 35 años que crecieron en la cultura occidental, que vienen aquejadas de las relaciones de pareja insatisfactorias y cuya relación con la madre ha sido problemática por falta de sintonía ("malattunement") en la relación. La problemática de estas pacientes viene acompañada de baja autoestima y, muy frecuentemente, de problemas alimenticios. En mi experiencia clínica ha sido el paciente tipo más frecuente y me ha permitido desarrollar un "esquema de trabajo" que me gustaría compartir.

Estas pacientes han crecido con una idea falsa del amor que se puede observar perfectamente en las películas Disney, con las cuales yo también crecí. Lo que todas las películas tipo Disney tienen en común es que tratan de una chica que es perfecta, pero nadie la ve hasta que llega el príncipe y la elige a ella y la salva de un ambiente difícil. Entonces todo el mundo la ve y se da cuenta de lo perfecta que es. También muestran una relación de pareja irreal e idealizada o, más bien, con un enamoramiento idealizado, ya que todas acaban con un final feliz cuando la relación apenas ha empezado.

Cuando pienso en mi propia experiencia con Disney, me acuerdo de una escena cuando a mis 6 años estaba viendo la película "La Bella y la Bestia" y al despertarme por la mañana no pude para de llorar. Mi madre me preguntó qué me pasaba y le dije: Es que yo quiero ser Bella. Tardé muchos años en entender por qué lloraba tanto por querer ser Bella. Años después, y gracias a empezar a ejercer como psicoterapeuta, me di cuenta que quería sentirme tan especial y elegida como se tiene que sentir una princesa y quería que alguien, como un príncipe, me salvara de mi mundo, en el cual yo no me sentía vista. El príncipe sería la solución perfecta a la falla narcisista. Lloraba porque no veía otra solución para escaparme de mi mundo y acabo de ver una opción pero sabía que por mi edad, no me podía pasar, porque era solo una niña.

Además, tanto yo como todas las chicas de mi edad jugaban con Barbie. Otro ideal que nunca se puede cumplir. Cuando eres niña, tienes que crecer, y piensas: cuando crezca, seré Bella o Barbie. Pero cuando creces, te das cuenta que no puedes llegar a cumplir con este ideal. Es una constante frustración de nunca llegar a ser tan perfecta como crees que deberías. La culpa no le quiero echar a la marca Disney ni a la marca Matel. No todas las chicas que crecieron en mi generación tienen el mismo problema. Disney y Matel solo fomentan o desencadenan algo que ya está en nosotras. 


\section{Viñeta clínica 1}

María*, me pide cita porque está muy celosa y sabe que esto no es normal. Es una chica alta y muy delgado, guapa, bien vestida, de 30 años. Está en una relación de pareja estable, aunque recién divorciada. Tiene mucho miedo que su novio la deje porque no va a soportar "los pollos que ella le monta". Esta celosa por otras mujeres y sobre todo por la relación que él tiene con su madre, que es muy estrecha. También me comunica que tiene baja autoestima y no le gusta su aspecto. Es perfeccionista.

¿Qué hacemos con este tipo de problemática? ¿Por dónde empiezo?

\section{Construir el contexto}

El psicoanálisis relacional pone mucho énfasis al contexto y a mí personalmente me parecen los fundamentos de cualquier proceso terapéutico. Construir el contexto causa que la paciente empieza a contar su vida y entonces hace las primeras asociaciones. Muchas veces las pacientes nunca habían puesto en palabras lo que les ha pasado y nunca se habían preguntado sobre lo que era importante y qué impacto tenía esto sobre ellos. Construir el contexto no solo es registrar las experiencias sino es una oportunidad de darles un nuevo sentido.

\section{Ejemplo de construir el contexto con María:}

Tengo 2 hermanas, soy la mediana. Tenía muy buena relación con mi padre. Con mi madre no tanto. Es decir, ella tenía una muy buena relación con mis hermanas. A mí me exigía mucho. Nunca le gustaba lo que yo hacía y siempre quería más y más. Mi padre era muy cariñoso. A veces nos quedábamos solos los dos hablando en la cocina hasta la noche. Se podía hablar de los sentimientos con él. Con mi madre no. A ella solo le importaba lo material.

En lo que me cuenta María sobre su contexto, a priori, no tiene por qué haber algo "malo". No obstante, vamos construyendo hipótesis sobre los posibles caminos para tomar e investigar con esta paciente.

\section{Comprensión}

El contexto es lo que nos ayuda a comprender la situación actual. El siguiente paso sería poder entender los síntomas de la paciente a través de su pasado. Por eso escuchamos el contexto de la paciente desde la perspectiva de su queja principal - los celos, el perfeccionismo. Buscamos la escena modelo que nos permite anclar los síntomas y referirnos a ella a lo largo de todo el proceso terapéutico. 
La escena modelo es algo que va contando la paciente y nosotros lo "rescatamos" y lo "miramos bajo lupa", analizamos y vemos que este es el micro-proceso que representa al macro-proceso. La escena es modelo porque refleja perfectamente los sentimientos que la hirieron y se repitieron reiteradas veces.

Al escuchar el contexto de María, me contó un acontecimiento que pudimos rescatar como escena modelo:

Cuando era niña mis dos hermanas se encerraban en la cocina con mi madre, yo tenía la habitación al lado de la cocina, pues lo escuchaba todo. Al principio entraba, pero las voces se paraban, nadie me quería ahí, así que dejé de intentar. Me sentí muy mal cada vez que las escuchaba ahí.

La pregunto a María: ¿Qué sentías tu entonces? Me imagino que tenía que ser muy doloroso para ti.

Gracias a resaltar la importancia de esta escena y de las emociones que ella pudo experimentar, llegamos a entender que prevalecían los sentimientos de rechazo y de envidia.

¿Por qué esta escena es modelo y por qué es tan importante? Porque es necesario que ella la conecte con la actual y que conecte con su dolor.

Poder darles sentido a los síntomas de la paciente es algo que cura per sé. El mundo deja de ser inseguro porque entendemos cómo funciona. Es clave poder conectar esta escena con otra escena modelo - la actual.

\section{¿Cómo encontramos la actual?}

Cundo María me cuenta su queja principal: soy celosa, yo indago desde la posición de mucha empatía y mostrando comprensión (es muy importante esta posición del terapeuta porque ella ya se siente culpable por sentir celos).

Cuando estoy con mi novio en un bar y hay otras chicas y mi novio habla con otras y se lo pasa bien, yo me siento obsoleta y siento que, si él se lo pasa mejor con ellas, qué pinto yo ahíy tengo ganas de huir. Pues me muestro ofendida, pero digo que no pasa nada y espero que mi novio vaya detrás. Si no va, me siento que no me quiere. Si va, me siento culpable porque sé, que mi reacción no es sana pero no sé cambiarla. (De hecho, muy pocas chicas al principio se dan cuenta que su reacción no es sana).

Esto es lo que podríamos llamar el bucle de feedback o el círculo viscoso del cual habla Paul Wachtel en su libro "Cyclical Psychoanalysis". En el bar cuando ella ve que el habla con otra 
chica y se lo pasa bien, ella se vuelve gruñona e histérica. Esto causa que el novio no se lo está pasando bien con ella. Por lo cual sí que ella tenía razón que él se lo pasaba mejor con otra. Aquí es muy importante ver que las consecuencias son una profecía auto cumplida de su intento que esto no pase y justo lo provoca.

Una frase que me gusta mucho usar y que me funciona muy bien con estas pacientes es: Si lo sientes, es por algo y vamos a explorar juntas por qué es. Y trabajaremos para cambiarlo porque te hace daño a ti.

Esta frase me ayuda a que ellas sientan la conexión entre sus sentimientos y el sentido común, que no se echen culpa, que no se sientan "locas". Pues exploramos juntas a darle sentido a lo que le pasa. Esta es nuestra escena modelo actual. La enlazamos con la escena modelo pasada para construir un puente entre ellas.

Por lo cual, cuando ella me cuenta la escena de la cocina, paramos aquí y miramos de que ella conecte los sentimientos y que vea que su reacción de ahora es exagerada pero para el contexto de ahora, pero conociendo su contexto de antes no es, porque ella reacciona ante la repetición de aquella escena que era muy doloroso pero entonces ella no pudo compartirlo con nadie ni nombrar los sentimientos. Se echaba la culpa a si misma por sentir envidia por sus hermanas igual que ahora siente culpa por sentir celos por su novio.

\section{Los detonantes y los mantenedores}

La terapia semanal se convierte en el análisis de los detonantes y de los mantenedores, que Paul Wachtel llama cómplices en su libro. Por detonantes me refiero a estas situaciones del presente que de alguna forma causan, que se activen ciertos mecanismos del pasado, como si causaran que se encienda el piloto automático y seguimos los viejos caminos neuronales.

Lo mantenedores, por otro lado, son estos mecanismos que causan que no se extinga el mecanismo o que sea tan difícil cambiarlo.

Hablando de la patología de las mujeres Disney, estas chicas se sienten insuficientes pese a ser tan perfectas porque siempre consiguen que la gente en su alrededor las halague o las admire, tienen sus sistemas de causar esta reacción en los demás. Suelen decir que no son tan perfectas y que son gordas y todo el mundo las asegura que no es así. Cuando van al examen no paran de decir lo mal que lo van a hacer porque no han podido estudiar nada y luego sacan un 10. Por lo cual, la próxima vez, todo el mundo les dice que lo van a hacer perfecto como siempre. Este mecanismo causa que de alguna forma entran en la trampa de tener que cumplir con ser perfectas porque es lo que todo el mundo piensa de ellas. Ellas lo que más temen es que resulte que no son tan perfectas y que salga la verdad a la luz. Por lo 
cual entran en el bucle de tener que demostrar contantemente que son perfectas. Porque, de alguna forma, temen que si no lo son, el mundo no las aceptará o no las querrá, como hacían sus progenitores.

\section{El punto de inflexión}

En el proceso psicoterapéutico puede haber varios puntos de inflexión, no tiene por qué ser uno. En el caso de esta paciente es cuando ya tenemos suficiente información sobre el contexto, hemos hablado de los detonantes y ella de repente cuenta algo que, o yo, o las dos, podemos conectar con algo que cambia la forma de comprender la historia. Fue el momento cuando hablando de su anterior relación de matrimonio, cuando estuvimos indagando sobre el porqué se casó, me dijo: para huir de casa. Le pedí que desarrollara este tema. Gracias a este momento yo entendí porque le molestaba tanto la relación entre su novio y su madre.

La relación con su padre fue muy estrecha, incluso llegamos a llamarla incesto blanco. Él le contaba cosas muy íntimas de la relación con su madre, y esperaba que ella hiciera lo mismo. Ella se sentía tan bien que alguien le hiciera caso, que compartía con su padre todos los detalles y sentimientos.

No obstante, ella tuvo un gesto de la salud. Algo que paradójicamente pareció una decisión suya equivocada - casarse a sus 20 años. Cuando vino a terapia se sentía incluso culpable y mal consigo misma por ser tan "tonta". Se casó con un hombre equivocado. Pero que habría sido peor: ¿quedarse más en casa enganchada a esta relación tan estrecha con el padre o casarse con quien sea para huir de casa? Ella me dijo: ahora que lo estamos hablando me doy cuenta que yo sí que por dentro quería huir de casa, esto no era sano.

Igual de poco sana parece ser la relación que tiene su novio con su madre, que tanto le recuerda a la relación que tenía ella con su padre. Me comenta: Ahora mi novio está cerca con su madre haciendo lo mismo y yo lo veo y él no lo quiere ver y me llama loca a mí.

Este suele ser el punto de inflexión también en la relación, porque la paciente se da cuenta que no es ella la única culpable de los problemas o de los enganches que se han creado, algo que los psicoterapeutas solemos asumir a priori. La psicoterapia de pareja no es el tema de este artículo, por lo cual no lo desarrollaré. No obstante, me gustaría mencionar que este es el momento cuando estas pacientes hacen terapia de pareja, su pareja va a terapia, o, en algunas ocasiones, se acaba la relación de pareja porque ella ha cambiado y el novio no. 


\section{El cambio}

Bueno, ahora lo entiendo, ¿pero ahora qué hago con todo esto?

Esta es la pregunta que he escuchado varias veces. $Y$ de hecho es una muy buena pregunta. Porque solo entender parece no ser suficiente. Yo suelo contestar a estas pacientes que el hecho de entender significa que ya tenía que pasar un gran cambio en ellas. Porque han sido capaces de ver estas cosas que son tan difíciles. Le dije a María: Es muy doloroso empezar a ver a tu padre no como tu salvador sino como un hombre inseguro que necesitaba a su hija para poder hablar de sus problemas. Tú has sido capaz de verlo, de cambiar tu perspectiva. Eso es porque aquí en terapia, juntas, hemos podido darte las herramientas necesarias para que fueras más fuerte.

Sin embargo, este es el momento en el que vi muchos impass. Seguimos hablando pero cada vez descubrimos menos, como en la curva del aprendizaje que crece rápido al principio, pero con el tiempo no se ven mucho cambios.

Ahora es el momento de intentar "saltar al agua" y a ver qué pasa. Yo lo llamo trabajar en dos niveles paralelos, uno más profundo, analítico, y otro más superficial, cognitivoconductual. Les animo a estas chicas a dar el paso, decirles que necesitan creer que sí que están preparadas para hacerlo (Como sería, por ejemplo, dejar que el novio salga solo con otra gente). Y cunado salten, me cuentan cómo ha ido. Si ha salido bien, repetirán los nuevos patrones hasta que se automaticen. Si no, miraremos juntas que es lo que ha ido mal. Si consiguen saltar es porque han sido capaces de tomar consciencia de su cambio en el momento y si no, lo hacemos a posteriori. Me gusta utilizar la metáfora de hacer nuevos caminos neuronales como si fuera un bosque de toda la vida. A veces vamos a caer en los caminos viejos pero si tomamos consciencia, podemos atrevernos a crear nuevos y a ver a donde nos llevan. Sin embargo, para poder hacer eso y para que el cambio sea duradero, es necesario tener el proceso analítico previo que cambia nuestra perspectiva y nos da confianza en nosotros mismos. Algo por dentro tiene que cambiar para que podamos cambiar la conducta.

\section{Viñeta clínica 2.}

Ahora utilizaré unas pinceladas del caso de Jessica* para centrarme más en la relación con la madre y sus consecuencias en la salud mental: su inseguridad, necesidad de perfeccionismo y sus relaciones de pareja.

Jessica consulta porque no está feliz y a veces se queda en la cama llorando y no puede parar. Siente mucha envidia, se compara sin parar con los demás, es celosa en su relación de pareja. 
Es una chica muy guapa, muy delgada, perfeccionista, la mejor estudiante y la mejor trabajadora. El perfil con el cual cumplen probablemente todas las chicas a las que me refiero.

Las madres de estas chicas suelen cumplir con estos tres criterios que comentaré a continuación.

1. Apego ambivalente: escena modelo. Jessica cumple 11 años. Su madre le organiza la fiesta de cumpleaños y junto con su padre le regalan un día en Port Aventura con una amiga. Jessica va y se lo pasa bien. Cuando vuelve, su madre está molesta con ella. Pero no dice nada. No explica. En su comportamiento y forma de ser se nota que algo no está bien. Jessica no entiende qué es lo que ha hecho mal. Pero se siente muy mal. Se siente culpable. Su madre está limpiando la casa. Jessica le pregunta: ¿Qué pasa mama, he hecho algo mal? No no, me alegro que tú te lo estabas pasando bien mientras que yo tenía que limpiar la casa después de la fiesta. Pero no pasa nada. Tu descansa que seguro que ha sido un día duro para ti.

Jessica se va a su habitación sin entender que pasó, se siente culpable por haberlo pasado bien. Se crea una asociación emocional en su cabeza: si te lo pasas bien, otros lo pasan mal, eres culpable. Mejor no pasarlo bien nunca.

Hoy en día Jessica no es capaz de relajarse y pasarlo bien. Es muy controladora. Siente envidia por los demás cuando se lo pasan bien.

2. Madre insegura de sí misma, en casi todos los casos obsesionada con su aspecto físico, de la forma perfeccionista (a dieta toda la vida o yendo a gimnasio cada día) o con sobrepeso intentando siempre mejorar. La fijación en la superficialidad y la fijación en lo que ven los demás es algo que estas madres trasmiten a sus hijas. Como si les dijeran: Tienes que ser perfecta para que te quieran. Estas madres se fijan mucho en el aspecto de sus hijas, y no habría nada malo en ello si no fuera a coste de ser felices. Estas chicas tienen la tendencia a mirar a fuera y no adentro: Mientras que la gente no lo ve, no pasa nada. Yo me puedo sacrificar para que se vea que soy perfecta. Varias de mis pacientes no son tan perfectas, lo contrario, lo quieren ser y no lo logran y se obsesionan con ello. Cuando vienen, suelen decir que quieren tratarse para adelgazar, no para estar mejor y más felices. En terapia nos centramos en cambiar la mirada hacia dentro y no hacia fuera. En quererse y cuidarse y tenerse en cuenta y saber protegerse en vez de ocuparse de que no se vea lo que pasa por dentro. 
3. Estas madres nunca parecen estar contentas con sus hijas, hagan lo que hagan. Siempre encuentran una pega a todo. Es normal que estas mujeres, cuando son niñas, buscan sentirse que sus padres les aprecien y que sean orgullosos de ellas. Si la madre siempre exige más, ellas también exigen más de sí mismas y literalmente se matan a estudiar o a adelgazar. Se están sacrificando para que alguien las aprecie.

Estos puntos podríamos resumir en la falta de sintonía. La madre está muy insegura de sí misma y no es capaz de conectar con su hija o con el verdadero self de su hija. La madre piensa que, si ella misma es perfecta, todo saldrá mejor, y este mensaje está intentando trasmitir a su hija. No obstante, le cuesta ver las necesidades de su hija, sus sentimientos, enfrentarse o sostener sus enfados y quejas porque ella misma no puede aceptar que no sea perfecta. Pero la hija no sabe que a su madre le cuesta. Ningún niño piensa que sus padres son falibles, lo contrario, tenemos la necesidad de creer que nuestros padres son perfectos, en las primeras etapas de nuestra vida. Entonces si la niña siente que algo está mal y la madre es perfecta, tiene que haber algún fallo en ella.

Para resumir, es importante resaltar que cada sesión psicoterapéutica pretende ser, como diría Alexander, una experiencia emocional o relacional correctora - experiencia de sintonía y de mirada adentro. El proceso psicoterapéutico con estas pacientes se centra en entender el contexto de la paciente, enlazarlo con su queja principal a través de las escenas modelo y ayudarle a ella ver y entender sus propios estados emocionales y mentales. Es clave mirar con ella, a cámara lenta, cuáles son los efectos que su patrón relacional causa en los demás y cuáles son los detonantes y mantenedores de su problemática.

\section{REFERENCIAS}

Alexander, F., \& French, T. M. (1946). The corrective emotional experience. Psychoanalytic therapy: Principles and application.

Wachtel, P. L. (2014). Cyclical psychodynamics and the contextual self: The inner world, the intimate world, and the world of culture and society. Routledge.

Ringstrom, P. A. (2014). A relational psychoanalytic approach to couples psychotherapy. Routledge.

Original recibido con fecha: 25-4-2017 Revisado: 30-8-2017 Aceptado: 30/og/2017 expresa. Este material es para uso científico y profesional exclusivamente y puede contener información clínica sensible. Los editores no se responsabilizan de los contenidos de los autores. Dirigir las consultas sobre derechos y autorizaciones a ceir@psicoterapiarelacional.es 